\title{
Antiquarian Books as Source of Environment Historical Data
}

\author{
Jürgen Schram, Rasmus Horst, Mario Schneider, Marion Tegelkamp, \\ Hagen Thieme and Michael Witte
}

Additional information is available at the end of the chapter

http://dx.doi.org/10.5772/56749

\section{Introduction}

In recent times historical environment situations became inevitable also for modern environmental analytic. They alone allow to evaluate an anthropogenic impact into the environment compartments. All prognoses to future in environmental sciences at least base on interpolations deduced from historical situations in combination of present situations. Mostly glaciology [1], [2] is a source of information about historical environment. Unfavourable for such a proceeding is the fact, that glacier mostly are situated at inhabited places [3]. So they reveal only global or supra-regional data. Data from cultural centre's nowadays only are taken by imission measurements, e.g. bones [4], monitoring the exposure of an individual to its environment.

We approach the task to receive information about the historical environment situation in settlement areas by examining historical well dated and localisable artefacts of the homo faber.

To make a product acceptable to such a strategy, it must fulfil some requirements, listed in the following:

- $\quad$ Property of an analytical passive sampler

- Common and widespread product

- Reproducible way of production (guild)

- Defined state at the begin of contamination

- Damage / manipulation must be evident

- $\quad$ Exact dating of the product

- Regional allocation possible

In the work introduced here, historical paper like antiquarian books are used as such a source of environment historical data specially for the environmental compartment of air and water. Antiquarian books mostly are fulfilling all listed requirements. 
The selected objects of study further must have a complete block with original binding/cover. They must be produced before 1840 ("handmade paper").

The paper of historical books can be allocated by their watermark, which is characteristic for the paper mill. It can be dated by the printing date of the book - lean production was necessary, because the amount of paper for one book project was so big, that long time storing was nearly impossible

The absence of water spots and/or conservatorial treatment makes sure that there is no unwanted contamination of the book (Figure 1).

The work is divided into two parts, one dealing with airborne contaminants [5], one with water-borne contaminants [6]. In both cases antiquarian books are used as source for environmental historical data.

\section{Antiquarian books and environmental airborne contaminants}

The degradation of books and papers in the last decade has been focussed at from science and the public. Historical storage conditions were taken into account as factors, but they are experimental not to be simulated under real conditions, because it is impossible to simulate realistically long time storing.

The first part of this publication herein precisely starts at this point. An attempt was made to detect the historical immigration of airborne pollutants specifically in books, so as to provide the basis for a long-term correlation between pollutants in the paper, the corresponding concentration of atmospheric trace components and the damage of the paper.

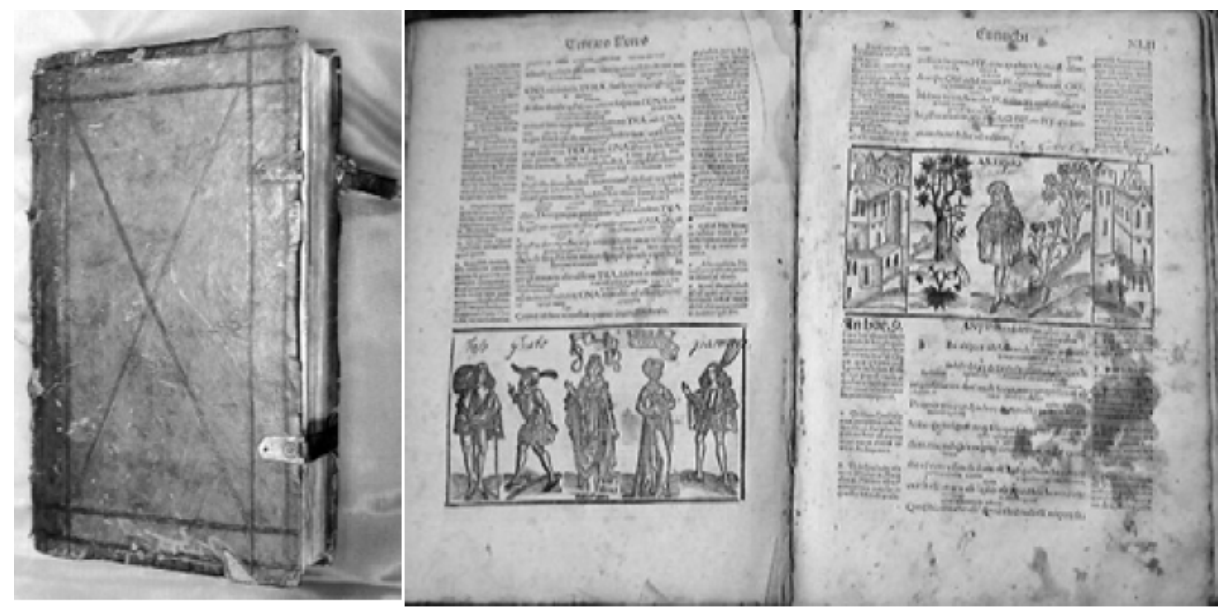

Figure 1. Ancient books, Terentius, 1499, not usable as source of historical environmental data because of obvious contamination 


\subsection{Volatile pollutants in paper and decay of paper}

The degradation of paper and books in the last decade strongly has been brought into interest in science and the public. The importance of environmental factors during storage in the libraries was highlighted and partially documented with current environmental analytical data. Historical storage conditions were discussed as important factors, however, both were only discussed in models - but no proof of the intrance of historical pollutants by atmosphere was given.

As part of the work described herein was set precisely at this point. An attempt was made to record the historical input of airborne pollutants specifically in bound antiquarian books [5].

In the focus of this study there are no exemplary studies on the adsorbability of harmful substances and at least their degradation mechanisms in the paper [7], [8]. Rather, as part of a comprehensive project, which is still running, the pollutants really trapped by the historical paper of the books were determined. Later the pollutants experimentally found to be present in library environment (via indoor measurements) in combination with kinetics of the uptake of pollutants in the book, should allow to estimate the situation of historical indoor environment and historical sources of contaminants.

The starting point for this study was the hypothesis that the paper of antiquarian books can serve as a passive sampler for air pollutants.

Components such as the cellulose of the paper play a role as a trap for a great variety of contaminants. This property of the cellulose is often used in the environmental analysis of gas samples for sample enrichment of various polar and medium polar contaminants such as Atmospheres [9], [10], [11]. This process will take place also in paper writing material.

This passive sampler system should contain information about the pollution that a book was exposed to, although of course not only the current pollutant inputs, but also historical contaminants / pollution must be considered.

Historical damage, e.g. of gas gangrene of leather materials due to the gas lighting of 19.century have to be taken into account during these investigations.

It is assumed that the significantly not air-permeable cover of books has a shielding effect for the passage of harmful gases.

So as a criterion for detecting a contaminant sampled via this mechanism is a concentration difference between the centre of an individual page and its edges, which are more in contact with the air surrounding the page.

One part of the overall project is to try to find a way that allows a correlation between pollutants in the paper, the damage to the paper and for modern inputs of pollutants in the concentration of atmospheric trace components of the current storage locations. 


\subsection{Contaminations in paper}

The decay of writing materials such as paper provides a non-negligible danger to the existence of entire libraries, and thus our cultural knowledge at all.

The damage is often catalysed by impurities in the writing surface either directly or causally induced [12]. Just trace elements are involved in a variety of ways in decay processes of cellulose. Such impurities can already produce in very small trace concentrations harmful effects.

They can be attributed to different sources. In principle, three mechanisms of entry of pollutants into books are to be distinguished:

Entry to the manufacturing process

Already in the production of written support materials, traces have been introduced into the material of pollutants. These can be direct (black-colored parchment) or as a result of their decomposition processes (ink corrosion) have a detrimental effect [13].

\section{Entry through restoration measures}

Conservation processes often bring chemicals into the paper. This entry can be wished (magnesium-Wei T'o the entry process, pesticides) or technically unavoidable (chloramine $\mathrm{T}$ residues after bleaching processes) done [14].

Input of pollutants from the environment during storage

Writing materials generally have a large internal surface that is covered with chemically reactive groups. They are therefore able to adsorb and thus to enrich pollutants from phases in contact with the material. The absorbed substances can cause damage (damaged paper in the field of cutting edge books) [15], [8].

\subsection{Mechanisms of pollutant entry into paper}

Of these damage processes in this part especially the latter damage mechanisms are investigated. The air surrounding the books is to be considered as a contaminating factor. For books which were stored for centuries, especially the historical situation is to be seen as the mostly important.

The possible components in the gaseous state, or bound to dust particles or aerosol droplets from the surrounding air migrate into the cellulose of the paper. These pollutants can be divided into two main groups:

- Molecular, stable in aqueous systems, usually non-polar compounds (pesticides, dyes, solvents)

- Polar with water ion forming compounds ( $\mathrm{SO}_{x}, \mathrm{NO}_{x}$, acids, amines)

The first group (molekular unpolare organic trace substances) according today's knowledge play only a relatively minor role in as initial substances of decay mechanisms. On the other 
hand polar inorganic and organic substances or ions in aqueous systems are very important. They seem to be the main cause of various damage mechanisms. Examples therefore include cellulose degradation processes by acidic components or oxidative degradation of cellulose, catalysed by traces of heavy metal [12].

In the project described here, therefore, an attempt was made to determine in the paper of selected books the concentration of some ionic impurities with a high damage potential.

As particularly significant thereby the material region nearby to the cutting edges is to be seen. There the ambient air comes into most intensive contact with the cellulose of the paper. These cutting edge regions are often already damaged, which visually clearly can be recognized.

A difference in the corresponding ion content between the centre and the cutting edges of a page reveals a adsorption of these compounds from the surrounding atmosphere in the border region of the books - so acting as a passive sampler.

Such a difference in concentration can't be attributed to the production of paper (Figure 2). The multiple folding of the individual printed sheets of paper before the binding of a book coincides that the edge region of such a sheed Is no longer the cutting edge of the book page.

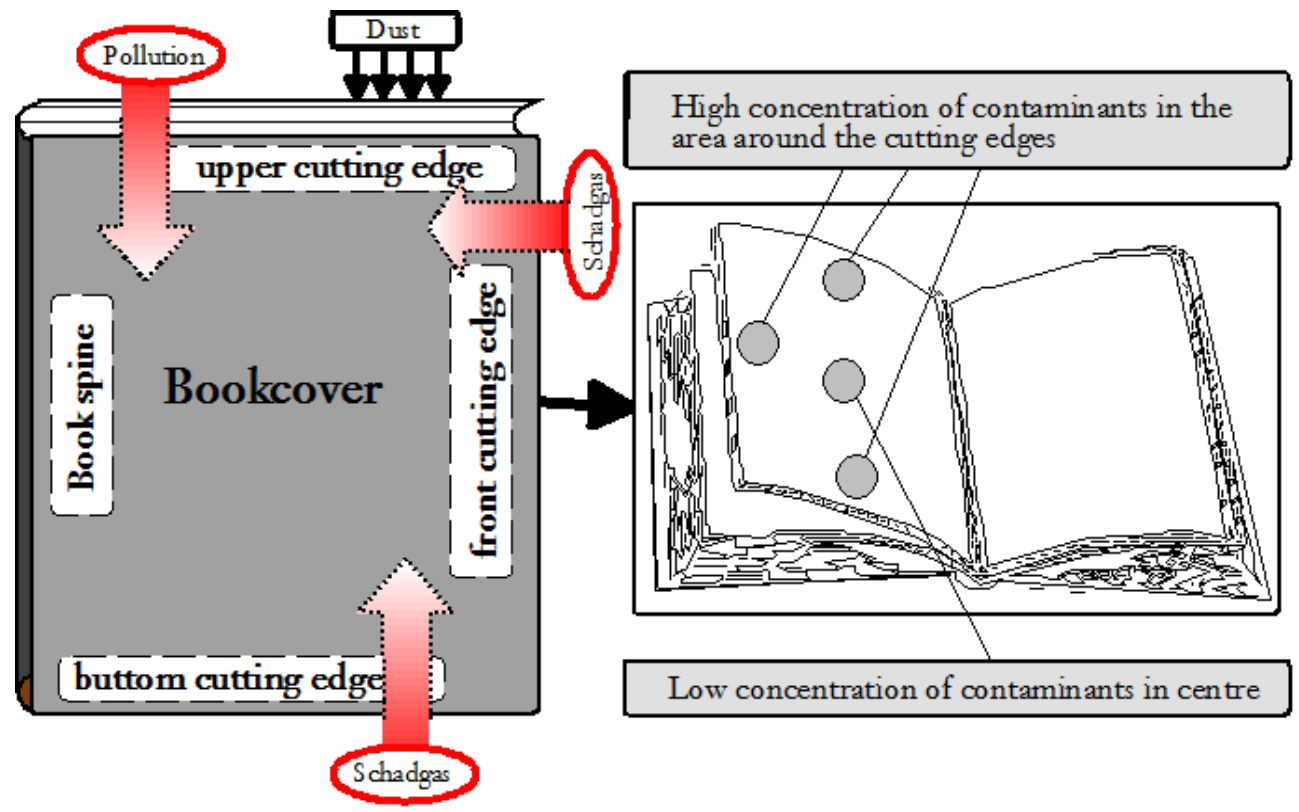

Figure 2. Mechanism of incorporation of contaminants into a book

As the source of this adsorption process some pollutant gases are obvious. Mostly they hydrolyse to the corresponding ionic components which can be detected in the paper:

- $\quad$ Acid gases 


$\begin{array}{lll}\mathrm{NO}_{x} & \rightarrow & \mathrm{HNO}_{2}, \mathrm{HNO}_{3} \\ \mathrm{SO}_{x} & \rightarrow & \mathrm{H}_{2} \mathrm{SO}_{3}, \mathrm{H}_{2} \mathrm{SO}_{4} \\ \mathrm{HCl} & \rightarrow & \mathrm{HCl} \text { (aqu.) } \\ \mathrm{CO}_{2} \rightarrow & \text { "H}_{2} \mathrm{CO}_{3} " \\ \mathrm{CH} & \rightarrow \\ \mathrm{R}-\mathrm{COOH} & \rightarrow & \mathrm{CH}_{3} \mathrm{COOH} \\ & \rightarrow & \text { R-COOH }\end{array}$

- Basic gases

$\mathrm{NH}_{3} \quad \rightarrow \quad$ "NH${ }_{4} \mathrm{OH}^{\prime}$

\subsection{Analysis of pollutants after the entry into the paper}

To solve the corresponding chemical analysis problem initially encountered an appropriate problem-matched sampling system was developed that meets the requirements for the analysis of unique cultural objects.

Since using reflective spectroscopy methods directly applied on antiquarian paper does not provide the necessary information (detection limits) specially with respect to the acidforming ionic components, eluates of the papers had to be examined.

One part of this work therefore was the development of techniques that allow to obtain aqueous eluates of well-defined locations on written antiquarian papers, without damaging the delicate system irreversible. Because of the cultural value of these books, it is necessary to work absolutely non-destructive with those objects.

Therefore some investigations had to be done with model papers. Normal filter paper, as used in laboratory was used to develop the non-destructive elution technique. Hereafter historical sheets of paper were utilised to develop the analytical methods, taking the matrix interference into account.

Finally a method was developed wherein the selected spots on a page were stamped by a cyclic rubber stamp with a saturated solution of paraffin to prevent scum rings and chromatographic effects. The encircled area was conditioned by spraying with a solution of $30 \% \mathrm{w} / \mathrm{w}$ ethanol in water for $10 \mathrm{~min}$. Afterwards it is clamped between two meandric polypropylene plates, guaranteeing a uniform washing of the conditioned area. It is rinsed thoroughly with a elution solution of deionised water $(2 \times 1.0 \mathrm{~mL})$ by a peristaltic- pump with a flow rate of $0.27 \mathrm{~mL} / \mathrm{min}$ - so eluting the adsorbed ions. The flushed area was $8,5 \mathrm{~cm}^{2}$.

Up to four clamp arms were provided with appropriate meanderic suction plates to eluate one page at three spots simultaneous. So - after appropriate pre-swelling of the paper - it is thus possible to eluate the antiquarian paper without permanently visible irreversible changes of the condition of the paper (Figure 3). An additional burden on the papers by an additional chemical entry will not occur with this method - on the contrary, the studied site is cleaned by washing with distilled water of pollutants. 




Figure 3. Elution system to determine the first elution of historical paper

The resulting solutions were analysed by capillary electrophoresis and ion exchange chromatography concerning its contend on harmful ions [16], [12].

These systems require sufficient small sample volumes $(0.8 \mathrm{~mL})$ and thus provide a careful and nondestructive method for the analysis in cultural and historical samples because each sampling at least represents a unavoidable interference in the cultural object [7], [17]. The detection limits of the system $\left(0.5 \mathrm{mg} / \mathrm{L} \mathrm{SO}_{4}{ }^{2-}, 0.2 \mathrm{mg} / \mathrm{L} \mathrm{NO}_{3}{ }^{-}\right)$were sufficiently small to prove the relevant concentrations.

\subsection{Objects of study concerning airborne pollutants}

We studied books of the 17th-18th century, that had been made from rag paper and not industrially produced papers.

Only those made from fermented and then shredded rags rag papers (up to ca.1840) allow the described procedure to determine the entry of acidifying substances via the gas phase. in contrast to modern manufactured paper, for there are many sulphur containing chemicals used in the production process (e.g. sulphite and sulphate pulp).

In total 11 books of the production period from 1607 to 1753 were examinated. All books except one had an intact cover, which came from the manufacturing time. In particular the following books were examinated from different sources:

- $\quad$ Lucas, F.; Concordantiae biblorum, Lyon 1612

- $\quad$ Spanheimius, F.; operum miscellaneorum, Leiden 1703 
- $\quad$ Luther, M. /, Klemmen, C. Die heilige Schrift Neuen Testaments, Tübingen 1729, Part I

- Luther, M. /, Klemmen, C. Die heilige Schrift Neuen Testaments, Tübingen 1729, Part II

- De Lambertini, P.C., De servorum beatificatione et beatorum canonizatione; Patavia 1743

- Wilischen, CF; Biblia parallelogram - harmonico exegetica, Leipzig 1753

In a second phase of 5 books from a library [17] were investigated, which were kept for about 300 years ago in the same room:

- $\quad$ Faber, M., Opus concionum Tripartitum; Verdussen, Antwerp 1663

- Volume 1

- Volume 2

- Volume 3

- $\quad$ Adriani, H.; Catholycke seremoonen op all Epistelen end Gospels van de soundings end heylighe daghen van den gheheelen Jare; Verdrussen, Antwerp 1620

- Viguerius, J.; Institutiones thiological it sacris literis Conciliis doctoribus ecclesiasticis, Thomas Aquinas praecique D., Walter, Cologne, 1607

In each book different pages at four points were eluted (Figure 2) and analysed towards the content of $\mathrm{Cl}^{-}, \mathrm{SO}_{4}{ }^{2-}$ and $\mathrm{NO}_{3}$. One sampling point was the centre of the page, one in the middle of the top cutting line, one in the middle of lower cutting line and one in the middle of front cutting line. In some cases 6 points (Figure 4) were examined.

\subsection{Results and discussion of the adsorption of airborne pollutants in historical books}

All the books examined with intact cover showed a clear accumulation of pollutants $\mathrm{NO}_{3}$ and $\mathrm{SO}_{4}{ }^{2-}$ at the cutting edges of the book. The centre of each side was in average significantly lower contaminated with pollutants than the average range (by a factor 2 to 10 ).

The highest concentrations were apparent in the region of the head section, followed by the front and finally the foot trim. Diagram 1 shows exemplary values. For the borders of a paper in the book this difference can not be explained by the paper production but only by the entry of airborne pollutants into the cellulose of the edges of books. It is obvious here that the ions detected by hydrolysis of gaseous pollutants - have been formed - primarily through contact with the atmosphere. They are in good agreement with the above theories to the entry mechanism from the gas phase.

Apart from the adsorption of pollutants into the cellulose of the book, there are further possible processes, that can cause differences of concentrations of contaminants at diverse areas of a book. So the printing ink could be a source as well as the degradation of the paper. Furthermore the book cover could be a source of an input of chemicals into the cellulose. Comparing the distribution of contaminants from the first to the last pages in combination with the distribution on a single page allows to differentiate between these processes. Figure 4 illustrates this coherence. 


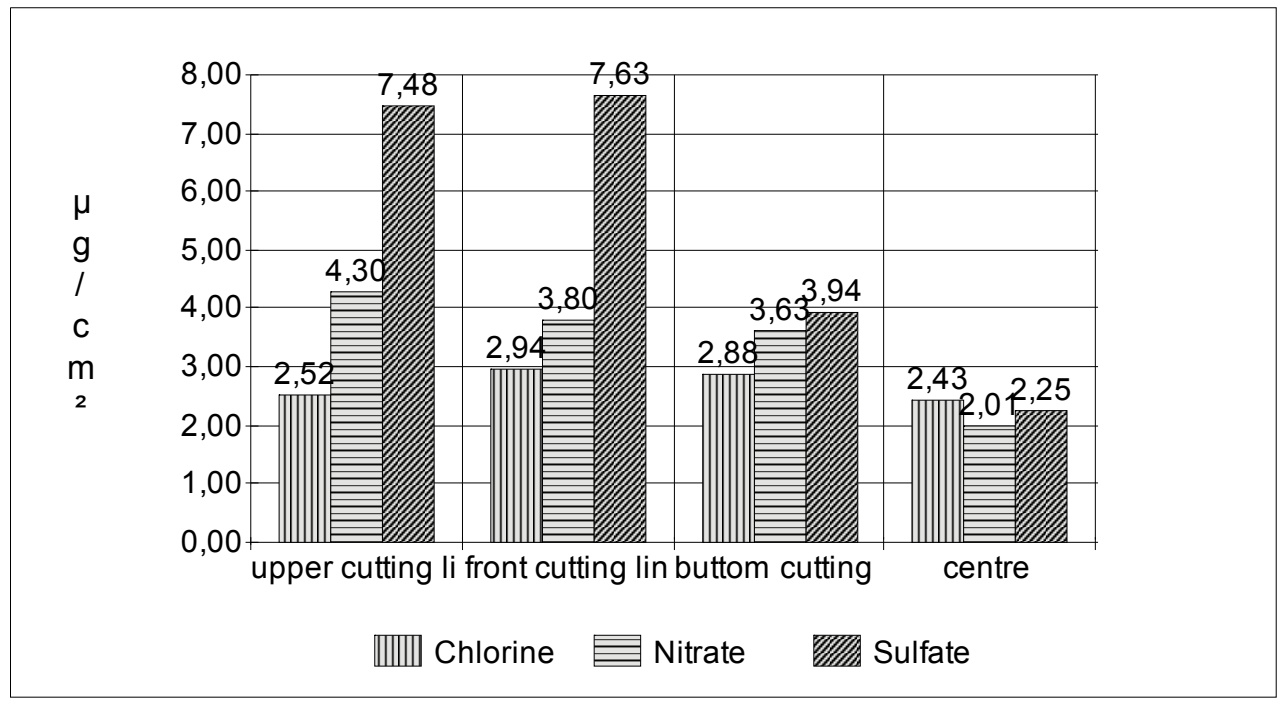

Diagram 1. Pollutant concentrations in De Lambertini, P.C.; Patavia 1743

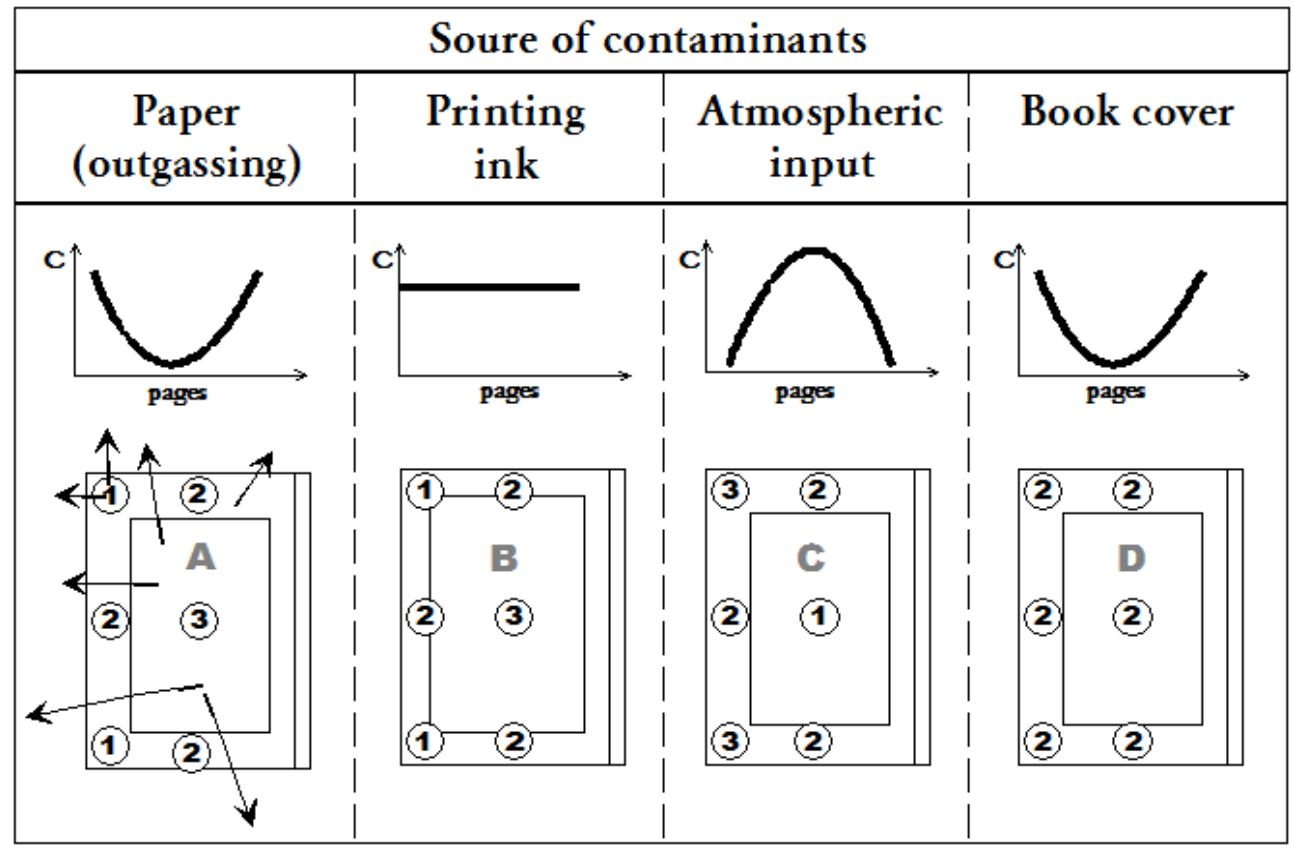

Figure 4. Causes for a variation of concentrations of contaminants within a book. Concentration differentiation at a single page and over the whole book allows to deduce the source of the contaminant. The numbers 1, 2, 3 symbolize the concentrations. The numbers are proportional to the concentrations. 
Looking at the distribution (Diagram 2) within the different pages of a book unsually an increase in the concentrations of contaminants is observed in the direction of the middle layers. This result can be understood by the shielding effect of book cover, which is more pronounced in the middle layers.

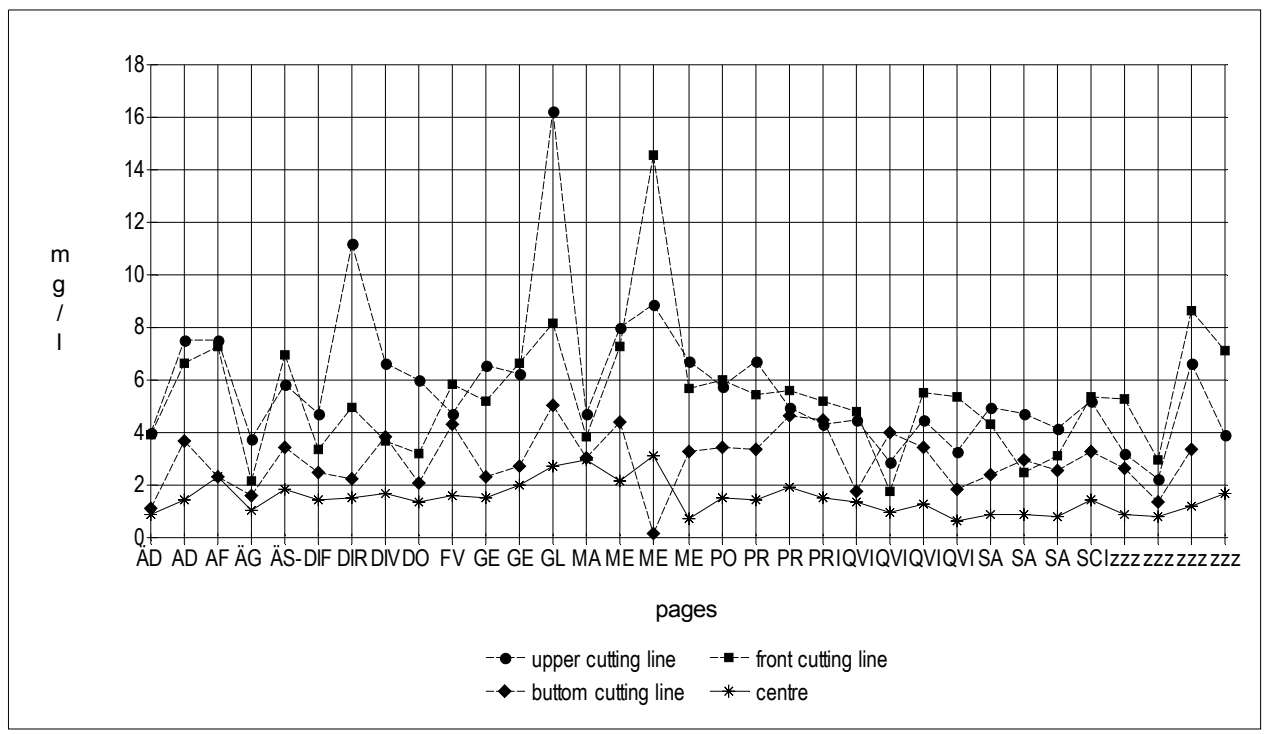

Diagram 2. Page depending distribution of nitrate concentration in the eluate $[\mathrm{mg} / \mathrm{L}]$ in Lucas, F., Lyon 1612

Page depending distribution of nitrate concentration in the eluate $[\mathrm{mg} / \mathrm{L}]$ in Lucas, F., Lyon 1612. The letters on horizontal axis shows the pagination of the book.

So for the first time, the entry of $\mathrm{NO}_{x}, \mathrm{SO}_{x}$, and $\mathrm{HCl}$ from the atmosphere into the finished book could be proved [5]. The concentration of the hydrolytic produced sulphate, nitrate and chloride ions were much lower in the edges of the pages of bound books, than in the centre (by a factor of 2-10) of the same pages. Thus it can be assumed that the cellulose of the book here acts as a trap for contaminants and so enriches over longer periods of time these pollutants. The upper cut edge of the books showed in all cases the highest pollutant concentrations. Studies of uptake of organic acids mostly showed a similar behaviour[15].

\section{Cellulose of antiquarian books as source for historical water data}

\subsection{Paper production and water contamination}

The production of paper in ancient times was a well defined technical process [18], which was "quality assured" by the strict regulations of the guilds. It was started with rags, which 
were sorted and cut. After fouling 1 month in water the resulting textile fragments were crushed with a pounding-machine to fibres. Cleaning of the fibre with river water happened in the HOLLÄNDER, a mills/shredder which allowed to produce a pulp of fibres. Finally the paper was produced with a sieve, containing the watermark, in thin layers. Water was pressed out and the paper was dried between layers of felt.

Paper production from pulp in a vat (e.g.16.Century) means at least the contact of cellulose with huge amounts of water of river (production water). It was the solvent of the pulp. With the energy of water mills the rag milling machines were powered. Therefore paper mills always were situated directly at a river. Nearly all pictures, showing the production process of paper, in the background show a river.

\subsection{Use of paper as source for historical water data}

The new approach to get environmental data uses the characteristics of production process described above. Cellulose has selective ion exchange properties - so it is able to trap (heavy) metal cations from water during production [19], [20]. The fibres adsorb contaminants (traces of metals) from the (river) water, forming a dynamic adsorption equilibrium.

This ion exchange process may be caused by traces of e.g. carbocylates, amines and aminoacids fixed to the fibres of the paper. It could be proofed, that there is a great variety of selectivity of different modern papers towards heavy metals, while alkalines and earthalkalines are much less attracted. Each metal can be characterized by an individual Langmuir / Donnan-plot on every special paper. These facts allows us to take into focus individual heavy metal -ions and their interaction with the paper.

This is stopped and conserved when the pulp is separated from the production water. With drying the heavy metal content is conserved within the paper and so stores in historical books.

To get information about the heavy metal content of historical water, it is first necessary to determine the adsorbed heavy metal content in the paper at some blank area (First elute). This process should be done without any destruction in a flow system. In the elutes, the heavy metal content is determined by Inverse Stripping Voltammetry ( $\mathrm{Pb}$ and $\mathrm{Cd}$ ) and Graphite Furnace Atomic Absorption Spectrometry (GFAAS) ( $\mathrm{Zn}$ and $\mathrm{Cu}$ ).

In a second step the eluted paper area is equilibrated in a non-destructive flow system under defined conditions with different concentration of heavy metals $(\mathrm{Cu}, \mathrm{Pb}, \mathrm{Zn}, \mathrm{Cd})$ to plot the adsorption isotherm. For the initially determined first elute, it is now possible to calculate the concentration of heavy metals in the production water of the pulp - and so of the corresponding river. A similar approach to nowadays contaminants was done with biofilm, allowing to determine illegal discharger in waster water technology [21], [22], [23].

Our approach is shown in (Figure 5 ). 


\section{Method:}

1.) Determination of the adsorbed heavy metal content in the paper

2.) Characterisation of the adsorption equlibrium in that very paper

\section{3.) Calculation of the historical contamination of the production water with heavy metals}
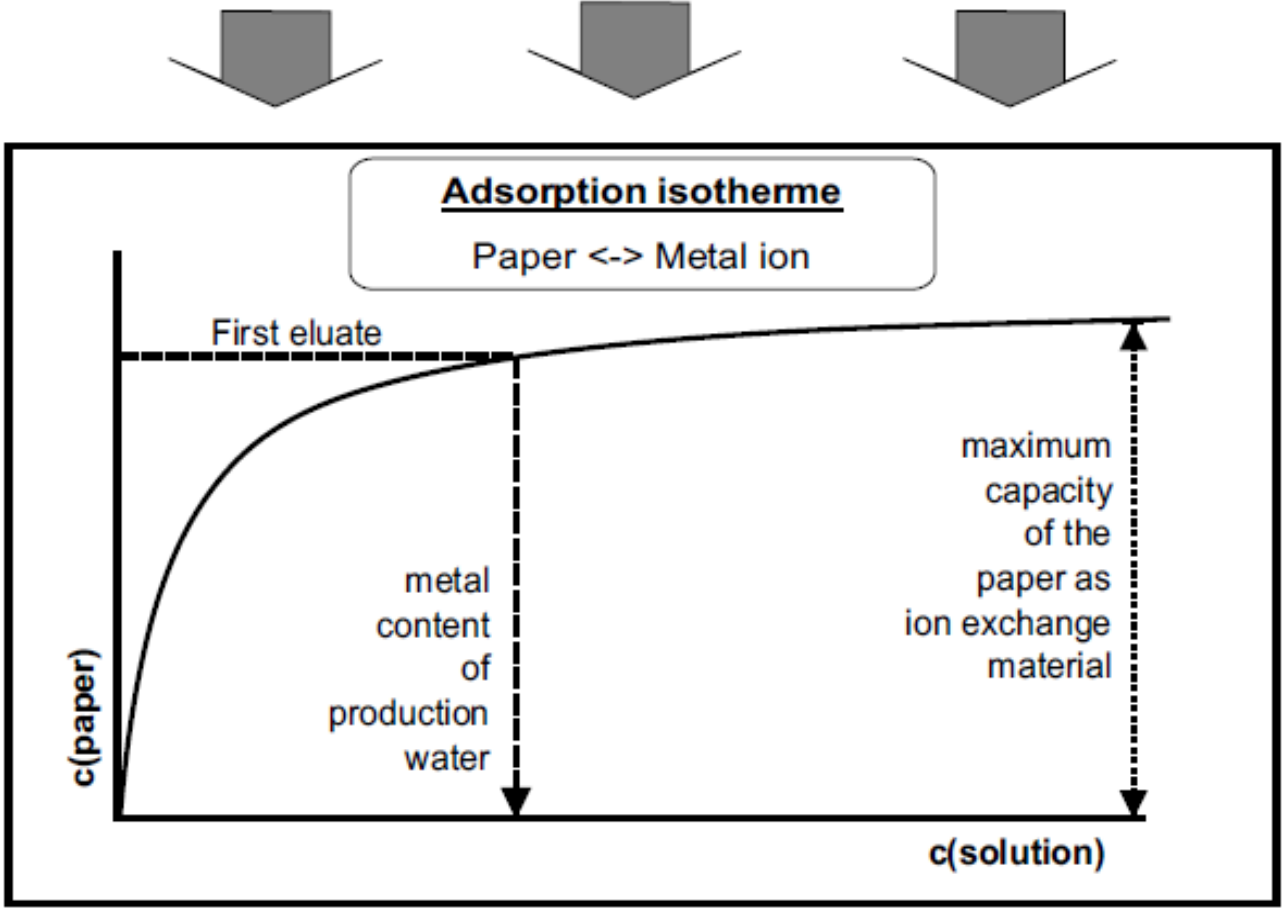

Figure 5. Principal approach to get environmental data from historical paper

\subsection{Experimental approach to determine historical water pollution}

Antiquarian books reveal a new source of environmental historical data. Because of their cultural value, it is necessary to work absolutely non-destructive with those objects.

Therefore some investigations had to be done with model papers. Normal filter paper, as used in laboratory was used to develop the non-destructive elution technique. hereafter historical sheets of paper were utilised to develop the analytical methods, taking the matrix interference into account.

Historical books without any damage and manipulation, fulfilling requirements above described, were selected in close cooperation with some libraries (Table 1). 
Book 1 Ioannis Maldonati

Societatis Iesu - Theologi commentarii in quattuor Evangelistas

Stefanus Mercatoris; Pontmousson, 1596

Book 2 Paciuchelli

Lectiones morales in Ionam Prophetam- Band II

Hieronymus Verdussen; Amsterdam/Antwerpen, 1680

Book 3 J. Meyer

Sive historiae Rerum Belgicarum

Sigismund Feyerabend; Frankfurt a.M., 1580

Book 4 Nicephori Callisti Xantopuli

Scriptoris vere catolici, ecclesiasticae historiae libri decem et octo .....

Sigismund Feyerabend; Frankfurt a. M., 1588

Book 5 Jan Jakub Scheuchzer

Geestelyke Natuurkunde

Petrus Schenk; Amsterdam, 1735

Book 6 Estius (Hessels van Est). / Petrus Lombardus

In quatuor libros sententarium commentaria, Vol 1

Jean de Nully; Paris, 1697

Book 7 Estius (Hessels van Est). / Petrus Lombardus

In quatuor libros sententarium commentaria, Vol 2

Jean de Nully; Paris, 1697

Book 8 Estius (Hessels van Est). / Petrus Lombardus

Commentariorum in epistolas apostolicas

N. Boucher, Rouen, 1709

Table 1. Books selected for the determination of process waters.

On one of the pages of the historical books 3 spots are selected. As already above mentioned they were stamped by a cyclic rubber stamp $(\mathrm{d}=40 \mathrm{~mm})$ with a saturated solution of paraffin $\left(\mathrm{RT}, \mathrm{mp} .80^{\circ} \mathrm{C}\right.$ ) in n-hexane to prevent scum rings and chromatographic effects. The encircled area is conditioned by spraying with a solution of $30 \% \mathrm{w} / \mathrm{w}$ ethanol in water for $10 \mathrm{~min}$. afterwards it is clamped in an elution system (figure 3).

The paper is clamped between two meandric polypropylene plates, guaranteeing a uniform washing of the conditioned area. It is rinsed thoroughly with a aqueous solution of 0,1 $\mathrm{mol} / \mathrm{L} \mathrm{Mg}\left(\mathrm{NO}_{3}\right)_{2}$ ( $\mathrm{pH} 3.7$ adjusted with $\mathrm{HCl}$ ) by a peristaltic pump with a flow rate of 0,27 $\mathrm{mL} / \mathrm{min}$.

There are taken several fractions (each $10 \mathrm{~mL}$ ) of the elute $(\mathrm{n}=4-8)$. They are analysed separately to indicate the completeness of the extraction (Figure 6). 


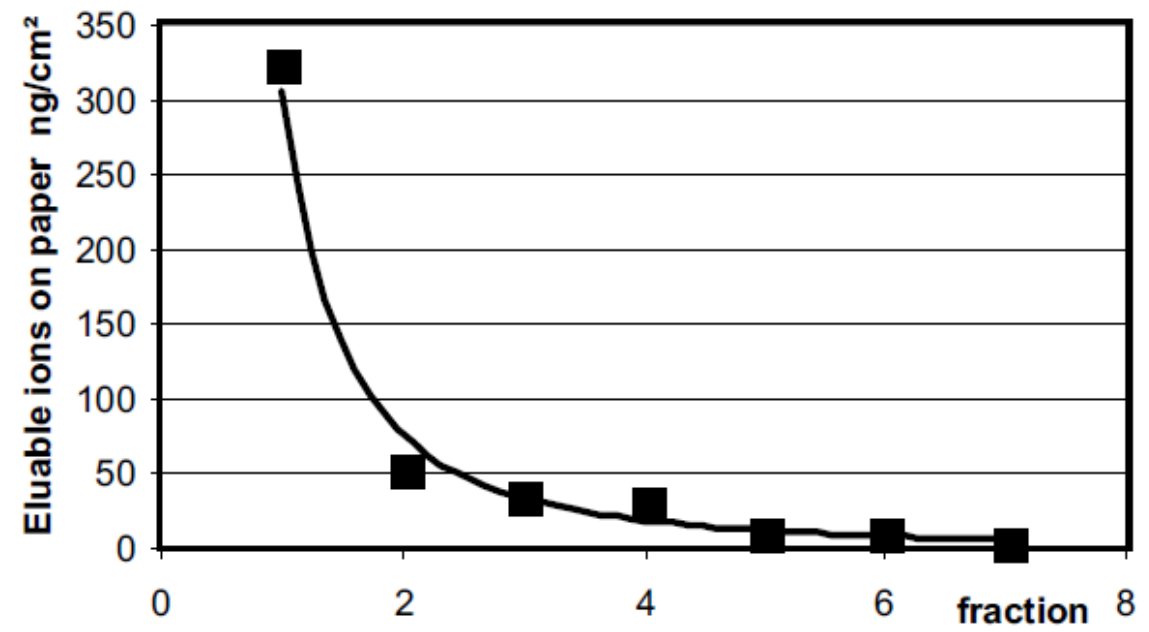

Figure 6. First elution. Concentration of the separated fractions

Afterwards in the flow-system the eluted paper spot is equilibrated for $100 \mathrm{~min}$ by cycling different concentration of heavy metals (mixture of $\mathrm{Cu}^{2+}, \mathrm{Pb}^{2+}, \mathrm{Zn}^{2+}, \mathrm{Cd}^{2+}$, each 10, 50, 100, $150,250 \mu \mathrm{g} / \mathrm{L}$ ) to determine the adsorption isotherm. The adsorption of metals on paper is done under defined conditions with deionized water $(\mathrm{pH}=5.7), 100 \mathrm{~mL}$ containing $0.0422 \mathrm{~g}$ $\mathrm{Ca}\left(\mathrm{NO}_{3}\right)_{2} \times 4 \mathrm{H}_{2} \mathrm{O}$ ( Figure 7). The solution cycling in the flow system was at least $25.0 \mathrm{~mL}$, which means a great excess of ions in relation to the ion exchange capacity of the paper. All these experiments were done at RT.

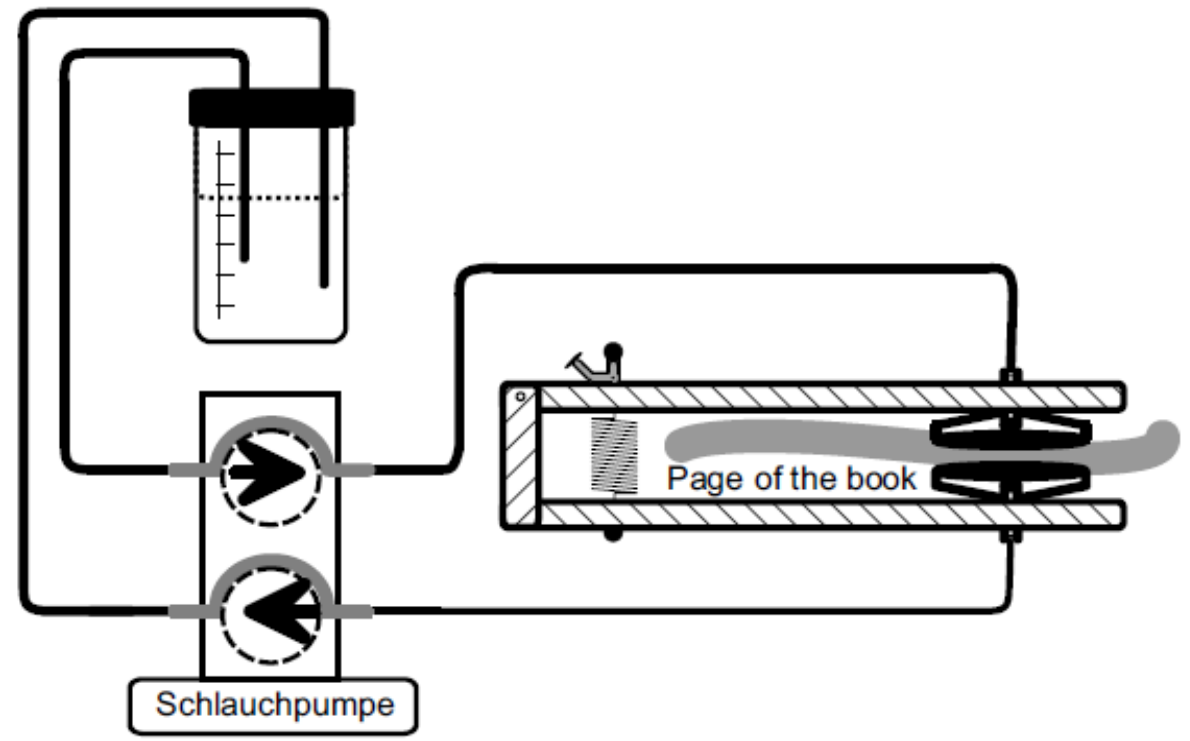

Figure 7. Equilibration system to determine the adsorption isotherms of historical paper 
Several samples of $100 \mu \mathrm{L}$ are taken during this process and analysed, revealing the kinetic of the extraction (Figure 8).



Figure 8. Kinetic of the adsorption equilibrium on filter paper

The determination of the elutes were done in case of $\mathrm{Cu}^{2+}$ and $\mathrm{Zn}^{2+}$ by ETV-AAS and in case of $\mathrm{Pb}^{2+}$ and $\mathrm{Cd}^{2+}$ with Inverse Stripping Voltammetry.

Atomic absorption was done using the Shimadzu atomic absorption spectrometer AA-6800, equipped with a high speed self reversal background compensation method (HSR). The injection volume was $20 \mu \mathrm{L}$. Only self reversal technique [24] allows to compensate background in the elutes of historical paper, which is invisible to deuterium technique. The instrumental operating conditions were standard reference methods for ETAAS $\left(\mathrm{Cu}^{2+}: 342,8\right.$ $\left.\mathrm{nm}, \mathrm{Zn}^{2+}: 213,9 \mathrm{~nm}\right)$

Differential pulse voltammetric determinations were done on the system $757 \mathrm{VA}$ of Metrohm at a hanging mercury electrode. In $\mathrm{NH}_{4} \mathrm{NO}_{3}$ electrolyte $(10 \mathrm{mmol} / \mathrm{l})$ the deposition was done for $90 \mathrm{~s}$ at $-1,15 \mathrm{~V}$, the sweep from $-1,15 \mathrm{~V}$ to $0,05 \mathrm{~V}$ with a sweep rate of 0,0595 $\mathrm{V} / \mathrm{s}$ and a pulse amplitude of $0,05 \mathrm{~V}$.

All calibrations were done by standard addition (Two additions).

\subsection{Results and discussion}

Some graphic examples for the resulting adsorption isotherm are shown in Figure 9. In the corresponding concentration rage, the adsorption isotherm is nearly linear. Using of the values of the "first elute", the process water concentration can be calculated. 


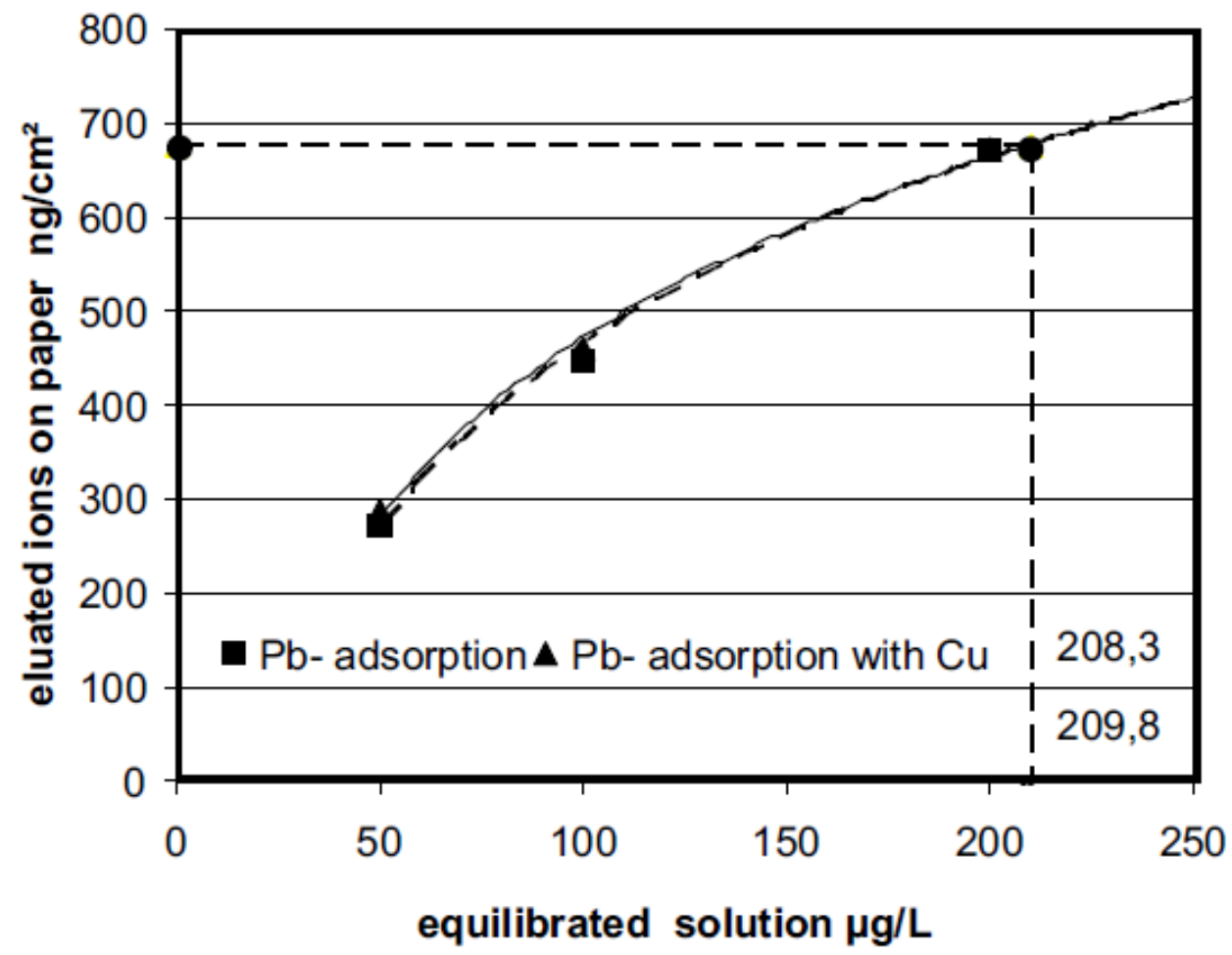

Figure 9. Graphical calculation of the composition of pulp process water of historical paper. The neglecting influence of $\mathrm{Cu}^{2+}$ - concentration $(200 \mu \mathrm{g} / \mathrm{L})$ on the adsorption $\mathrm{fo}^{2+}$ on 17.century paper is shown as well.

\subsection{Influence of matrix ions on the adsorption of heavy metals}

The basis of the determination of heavy metal contamination of historical (river) waters is the equilibrium between these metal ions and the fibre of cellulose of the paper. It works as a weak acid ion exchanger.

Ions like $\mathrm{Ca}^{2+}$ or $\mathrm{Mg}^{2+}$, present in normal surface water, compete against the heavy metal ions like $\mathrm{Cu}^{2+}$ or $\mathrm{Pb}^{2+}$ and so shift the balance of adsorption for those compounds towards the solution.

To be able to estimate the content of heavy metal ions in the paper production water, it first should be necessary to investigate the influence of these matrix compounds in the water on the adsorption isotherm

We could show, that the content of $\mathrm{Ca}^{2+}$ has no influence on the amount of $\mathrm{Pb}^{2+}$ and $\mathrm{Cu}^{2+}$ ions adsorbed on historical paper (Figure 10). There is no cross-selectivity for adsorption of heavy metals in presence of Ca-matrix $>50 \mathrm{mg} / \mathrm{L} \mathrm{Ca}^{2+}$. In consequence it is not necessary to know exactly the chemical composition concerning $\mathrm{Ca}^{2+}$ and $\mathrm{Mg}^{2+}$ of the water used at that time. 


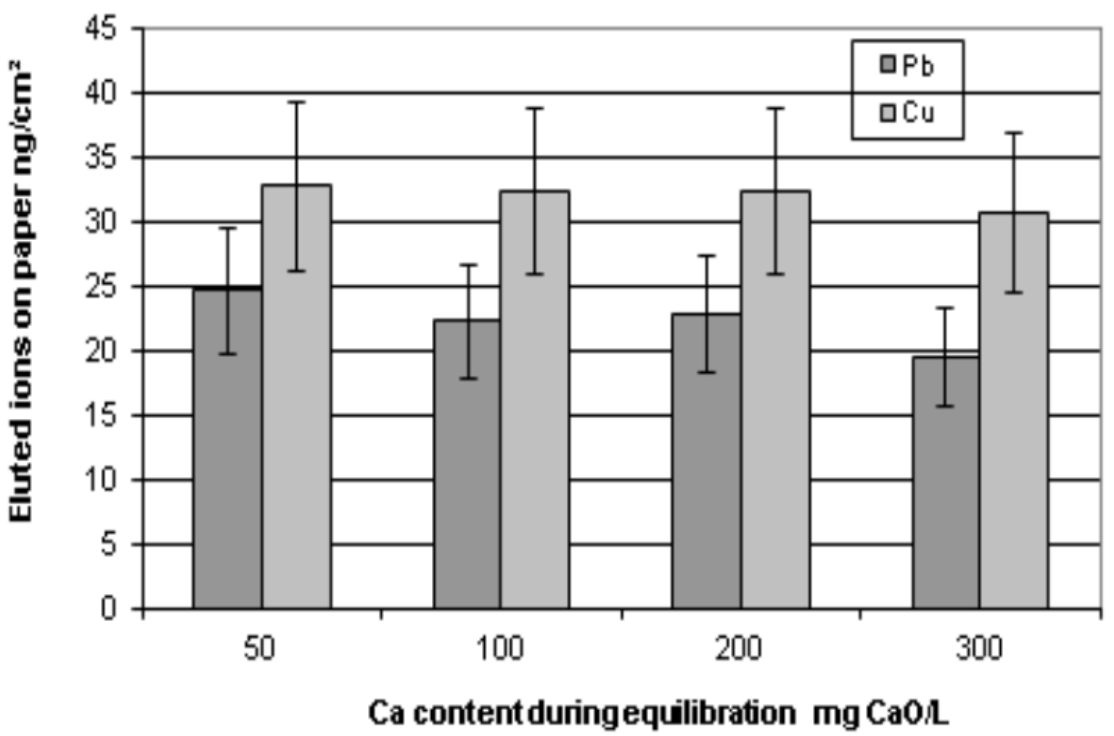

Figure 10. Influence of the $\mathrm{Cu}^{2+}$ - concentration (measured as $\mathrm{mg}(\mathrm{CaO}) / \mathrm{Lon}$ the adsorption of $\mathrm{Pb}^{2+}$ and $\mathrm{Cu}^{2+}$ traces (each $10 \mu \mathrm{g} / \mathrm{L}$ ) on 17.century paper

To determine the adsorption isotherm the paper is equilibrated with well defined concentrations of a multi element solution. This is only useful if the adsorption each heavy metal ion is independent of the other heavy metal ions, present during the equilibration 13 shows, that there is no dependence of the adsorption isotherm for $\mathrm{Pb}^{2+}$ ions of the presence of $\mathrm{Cu}^{2+}$ ions.

\subsection{Validation of the procedure}

New chemical methods normally are validated by the analysis of certified standard reference material or - if not available - by a reference to a well established analytical method [25], [26].

Both is impossible with the method presented here. Neither exists exists a "reference-paper" exists allowing the analysis of a "historical reference production water", nor a reference method analysing these water yet is established.

In consequence there are only the plausibility of the results as well as the plausibility of the process which can provide security for results or at least a low residual error probability.

For every point of the adsorption isotherm, a mass balance was calculated, showing that there was no irreversible adsorption in the paper/system or any contamination by the system. This mass balance furthermore ensures the plausibility of the concept.

Second the result of the calculated production water concentration should be the same within one page and in one book. Both could be proved, in several cases (Table 2). 


\begin{tabular}{ccccc} 
Page & Spot & $\begin{array}{c}\mathrm{Pb} \\
\mu \mathrm{g} / \mathrm{L}\end{array}$ & $\begin{array}{c}\mathrm{Cu} \\
\mu \mathrm{g} / \mathrm{L}\end{array}$ & $\begin{array}{c}\mathrm{Zn} \\
\mu \mathrm{g} / \mathrm{L}\end{array}$ \\
\hline 553 & 1 & 107 & 10,3 & 54 \\
553 & 2 & 83 & 10,3 & 69 \\
553 & 3 & 117 & 12,6 & 52 \\
561 & Mean(1-3) & 70 & 15 & 48
\end{tabular}

Table 2. Calculated $\mathrm{M}^{2+}$ concentration of historical production water on different spots of one page and of different pages of "Geestelyke Natuurkunde" of J.J.Scheuchzer, Amsterdam at Petrus Schenk 1735

These results are astonishing for the first eluates for example on some pages were significantly different concentrated. But these varying values were compensated by the fact, that all spot showed varied adsorption isotherm (Figure 11), smoothing the difference significantly. The isotherm is taken / used here as measured - no attempts were made to fit them to the BET-theories.

The standard deviation of the metal concentrations of the "first eluates" is much greater than the standard deviation of the concentrations calculated for the process water. This fact reveals local differences of the ion exchange characteristics of the paper, caused by different thickness or varied chemical micro structure and so - not at least - verifies indirectly the results of the corresponding production water. Different ion exchange systems in contact with the same water reveal - according our theory - the same water concentration.

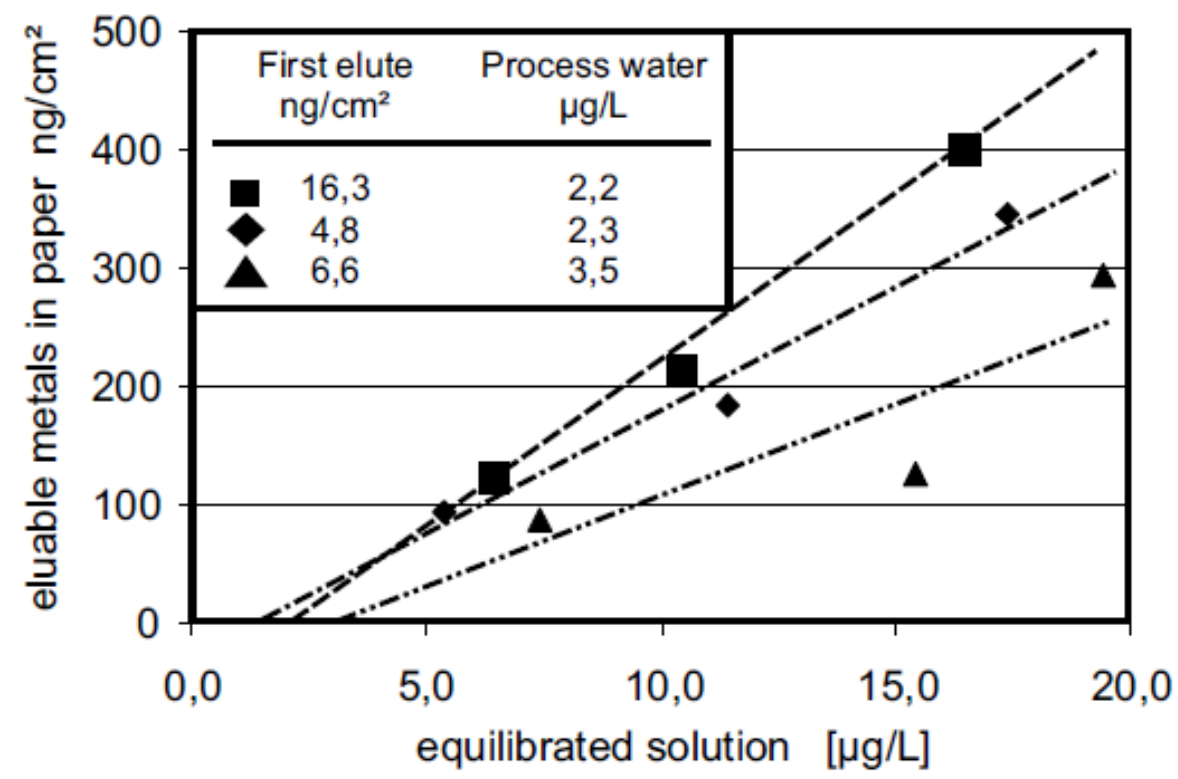

Figure 11. Inhomogeneity of different eluted spot of a page is compensated by the varied adsorption isotherms. 
At least the plausibility of the results can be assured by the books themselves. We looked into two books, being volume 1 and volume 2 of the same work "In quatuor libros sententarium commentaria" from Estius (Hessels van Est). Both volumes were printed in Rouen (Rothomagni) in the year 1709 by N. Boucher. Both papers had the same watermark, which yet couldn't be identified. It is very probably that both volumes were printed from the same lot of paper, having at least the same production water. There was sufficient compliance between the results concerning the heavy metal content of the production water (Table 3: ).

\begin{tabular}{lccccccccc} 
Book & Dated & \multicolumn{2}{c}{$\mathrm{Pb}$} & \multicolumn{2}{c}{$\mathrm{Cu}$} & \multicolumn{2}{c}{$\mathrm{Zn}$} & \multicolumn{2}{c}{$\mathrm{Cd}$} \\
& & $\mu \mathrm{g} / \mathrm{L}$ & $+/-$ & $\mu \mathrm{g} / \mathrm{L}$ & $+/-$ & $\mu \mathrm{g} / \mathrm{L}$ & $+/-$ & $\mu \mathrm{g} / \mathrm{L}$ & $+/-$ \\
\hline Estius Vol 1 & 1697 & 23,1 & 3,0 & 23,3 & 7,0 & 25,6 & 6,3 & 4,2 & 2,0 \\
Estius Vol 2 & 1697 & 17,4 & 3,3 & 35,7 & 6,0 & 28,7 & 8,2 & 5,3 & 2,2
\end{tabular}

Table 3. Comparison of the heavy metal content of a production water

The limits of detection (LOD) were calculated from the adsorption isotherm for each ion involving the LOD's of matrix containing elutes with the ETVAAS respectively Inverse Stipping Voltammetry using the $3 \sigma$ - criteria. The LOD allow to determine historical waters even in the range of modern instrumental analytic (Table 4: ).

\begin{tabular}{ccccc} 
Ion $(2+)$ & $\mathrm{Pb}$ & $\mathrm{Cu}$ & $\mathrm{Zn}$ & $\mathrm{Cd}$ \\
& $\mu \mathrm{g} / \mathrm{L}$ & $\mu \mathrm{g} / \mathrm{L}$ & $\mu \mathrm{g} / \mathrm{L}$ & $\mu \mathrm{g} / \mathrm{L}$ \\
\hline $\operatorname{LOD}(3 \sigma)$ & 0,93 & 0,92 & 0,35 & 1 \\
$\operatorname{LOQ}(5 \sigma)$ & 1,6 & 1,5 & 0,4 & 1,7 \\
\hline
\end{tabular}

Table 4. Limit of Detection (LOD) and Limit of quantification (LOQ) for the determination of historical process water with the help of antiquarian paper.

\subsection{Determination of historical production water.}

Historical books from the 16. to the 18. century, fulfilling the above described requirements, were selected and eluted in the above described manner (Figure 2). All books had at least folio format (width $>25 \mathrm{~cm}$, height $>35 \mathrm{~cm}$ ).

On selected pages, mostly from the middle of the books and without any printing the "first elutes" were leached out parallel at three spots of one page. In some books several pages were analysed.

In all selected papers it was possible to determine the adsorption isotherm for one $\left(\mathrm{Pb}^{2+}\right)$ or several elements $\left(\mathrm{Cu}^{2+}, \mathrm{Pb}^{2+}, \mathrm{Zn}^{2+}, \mathrm{Cd}^{2+}\right)$. 
So heavy metal contents of production waters were calculated from the paper of books of the 16.-18. century (Table 5:).

\begin{tabular}{|c|c|c|c|c|c|c|c|c|}
\hline \multirow{2}{*}{$\begin{array}{c}\text { Book } \\
1\end{array}$} & \multirow{2}{*}{$\begin{array}{l}\text { Page } \\
952\end{array}$} & \multirow{2}{*}{$\begin{array}{c}\text { Date } \\
\text {.of print } \\
1596\end{array}$} & \multicolumn{2}{|c|}{$\begin{array}{r}\mathrm{Pb} \\
\mu \mathrm{g} / \mathrm{L}\end{array}$} & \multicolumn{2}{|c|}{$\begin{array}{r}\mathrm{Zn} \\
\mu \mathrm{g} / \mathrm{L}\end{array}$} & $\begin{array}{r}\mathrm{Cu} \\
\mu \mathrm{g} / \mathrm{L}\end{array}$ & \multirow{2}{*}{$\begin{array}{c}\begin{array}{c}\mathrm{Cd} \\
\mu \mathrm{L} / \mathrm{L}\end{array} \\
<\mathrm{LOD}\end{array}$} \\
\hline & & & 9 & $+/-3$ & 21 & $+/-5$ & $3+/-0,7$ & \\
\hline 2 & 463 & 1690 & 18 & $+/-7$ & 67 & $+/-13$ & $1+/-1,4$ & $<$ LOD \\
\hline 3 & 93 & 1580 & 15 & $+/-2$ & 4 & $+/-5$ & $<$ LOD +/- 2 & $<$ LOD \\
\hline \multirow[t]{2}{*}{4} & 802 & 1588 & 23 & $+/-6$ & 28 & $+/-4$ & $4+/-1,5$ & $<$ LOD \\
\hline & 862 & & 34 & $+/-4$ & 21 & $+/-11$ & $3+/-1,5$ & $<$ LOD \\
\hline \multirow[t]{2}{*}{5} & 553 & 1735 & 102 & $+/-18$ & 61 & $+/-12$ & $11+/-1,3$ & $<$ LOD \\
\hline & 561 & & 70 & $+/-7$ & 48 & $+/-32$ & $15+/-1,4$ & $<$ LOD \\
\hline 6 & & 1697 & 23 & $+/-3$ & 25,6 & $+/-6,3$ & $23,3+/-7,0$ & $4,2+/-2,0$ \\
\hline 7 & & 1697 & 17,4 & $+/-3,3$ & 28,7 & $+1-8,2$ & $35,7+/-6,0$ & $5,3+/-2,2$ \\
\hline 8 & & 1709 & 51 & $+/-17$ & 182 & $+/-28$ & $41+/-18$ & $34+/-22$ \\
\hline
\end{tabular}

Table 5. Concentrations of heavy metals found in historical process waters.

The results contained from process waters from the Rhine, Main and Moselle region around 1580-1700 are comparable to modern uncontaminated surface water $\left(\mathrm{Pb}^{2+} \sim 1-10 \mu \mathrm{g} / \mathrm{L}\right)$, sometimes even higher than today [27]. Remarkable high values were determined in the process waters of the Netherlands around 1680-1735. Here concentrations up to $50 \mu \mathrm{g} / \mathrm{L} \mathrm{Zn}^{2+}$ and $100 \mu \mathrm{g} / \mathrm{L} \mathrm{Pb}^{2+}$ are to be found (Table 6). Specially in the region of Amsterdam and Antwerp, there are no fast flowing rivers as they are found at many other paper producing sites. It is known, that Dutch paper mills used windmills for energy supply instead of water mills. The water in those economical booming regions were only slowly flowing waters - in consequence of the geographical situation of the Netherlands. In consequence the waters of highly populated regions may be heavily loaded with hazardous pollutants. Lead - for example - at this time was commonly used, eg. for the production of tools, bullets, colours, metal type and water technology. Astonishing high values of heavy metals were found in a book, printed in Rouen in the year 1709. Specially the concentration of cadmium calculated from this paper seems to be very high - although this metal at this time was unknown. But $\mathrm{Zn}^{2+}$ in minerals[28] often is accompanied by $\mathrm{Cd}^{2+}$. If it is no modern contamination, the water came in contact with a (mineral) compound liberating a lot of toxic metals. 
After the whole analytical process, there is only a small imprint rested in the book. The stamped paraffin easily can be removed by heating with a flat iron between blotting paper. Apart from a water cleaned spot, there are no relicts (Figure 12) in the paper. So the procedure is conform to the strict requirements demanded for cultural heritage.

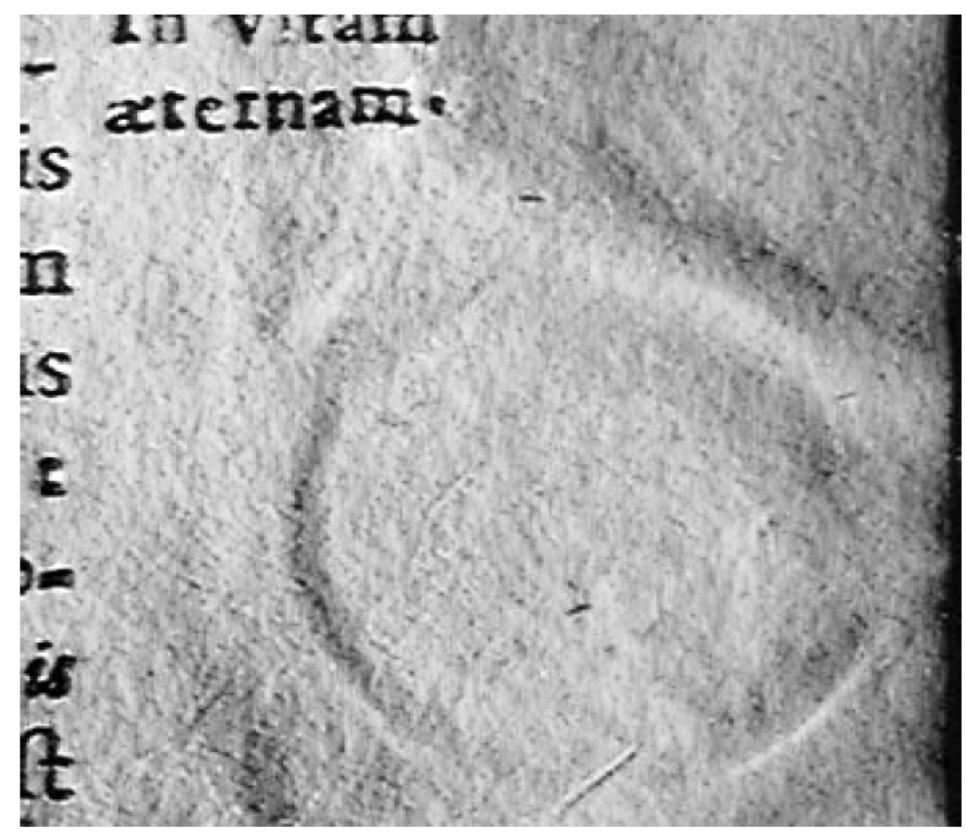

Figure 12. Picture of the paper after finishing the elution procedure

\section{Conclusion}

Historical contamination of environmental compartments can be seen as an experiment done by mankind. It allows - in its interpretation - to deduce answers for present environmental questions. So for example in presence the consequences of a change of climate is estimated by the data gained at the shelf ice layer in Arctic and Antarctica regions [29].

In the present work first steps to receive information about the historical environment situation in settlement area were done. We succeeded to determine the historical environmental compartment water by examining historical well dated and localisable commodities of the homo faber - old books and its paper.

It could be proved, that the atmosphere surrounding a book for centuries leaves traces in the cellulose of these books. In the center of the books, most anion forming acids are in lower concentrations than cutting edges, being in close contact with the atmosphere. The in historical times often emitted $\mathrm{SO}_{x}$ are in much higher concentrations to be found, than the 
actual dominant $\mathrm{NO}_{x}$, which in former times were very rare, for they are only produced wir modern high temperature burning processes.

So the acid catalysed decay of cellulose of antiquarian books becomes not only a consequence of modern production techniques, but as well of historical environmental conditions. If we succeed to understand the kinetics of the "passive sampler" book, we will even be able to describe these historical environments.

At present, the distribution of organic acids with the same technique and organic components with the principle of thermal extraction as well as its adsorption kinetics are under investigation in antiquarian books. In another long-term framework of this project is to explain the basis of the data thus obtained material is a correlation between damage type, degree of damage and concentration of individual pollutants present in the respective storage areas.

The information thus obtained will then provide the basis to develop in later projects concepts that allow to keep the content to be at particularly harmful gas components in library spaces as small as possible. Thought is the use of specific sorbent into the air intake side of the usually existing climate systems. From the experience gained here is a concept for the safe storage of records can be developed.

In addition, new contributions made to the environmental history, it might even succeed in using the information obtained to infer historical air pollution.

Ancient papers from well dated books are eluted without destruction of their paper and the resulting solution is analysed by ETAAS and Invers Stripping Voltammetry to determine the historical impact of metals. Afterwards in a flow-system the eluted paper spot is equilibrated with different concentration of heavy metals $\left(\mathrm{Cu}^{2+}, \mathrm{Pb}^{2+}, \mathrm{Zn}^{2+}, \mathrm{Cd}^{2+}\right)$ to plot the adsorption isotherm of that very spot.

It could be shown that the gained values concerning the content of some heavy metal ions in the pulp production water are plausible and seem to be realistic.

Yet there seems to be no contradiction to define the process water to be identical with the river water.

Such a correlation would be very essential for environmental history, Therefore it is necessary to discuss how realistic this approach could be. Nearly all contemporary pictures of the 16. -18. century show a beck or river directly "behind the windows of the building". So the water for the pulp production in most cases will be directly taken from the river / beck into the production container. In this filling process an additional contamination is not very probable. Contamination is more supposable by desorption from the container material. All bequeathed pulp mills use wooden casks or granite vats for the hand paper production. Both material should not have any significant influence on the heavy metal content of the production water. So to our opinion it is allowed to draw the conclusion that 
the production water is - concerning its contamination with heavy metal ions - identical with the water of the corresponding river.

So a new field of environmental data is accessible, allowing to evaluate historical environmental pollution. In moment one antiquarian book edition, stored in different libraries is in investigation to assure the principle.

\section{Summary}

Environmental historical data alone allow to evaluate the anthropogenic impact into environment. It is often forgotten, that all scientific predication of future development of environment is extrapolated from historical data. To receive information about the historical environment situation in inhabited regions, we approach to this task examining historical well dated and locatable products of the homo faber.

The work introduced here uses books as a source of environment historical data specially for the environmental compartment of water and air.

The paper of historical books is well dated by their printing and allocated by their watermark [30]. Often its owner signs reveal the history of the rooms were it was situated.

In the Instrumental Analysis cellulose is often used as a trap of traces of analyts. So in gaseous phase it enriches middle polar up to polar compounds as $\mathrm{NO}_{x}, \mathrm{SO}_{x}, \mathrm{HCl}$, organic acids or esters. In aqueous phases they additionally have to a certain extend the properties of ion exchanging polymers. Both processes can be used to make a new approach to aquire environmental historical data. Historical papers mostly are produced from cellulose - e.g. of a pulp produced by old tatters. For this process is well documented, it is possible to use them as passive samplers for airborne and aqueous contaminants - so opening an new method to get environmental historical data of the compartments air and water.

Airborne contaminants enter a book only by its cutting edge and not by the air-impermeable cover. In consequence a gradient between the centre of the pages and its border, representing an transportation process of the contaminants like in a analytical passive sampling equipment.

The cellulose of historical paper is a trap for traces of heavy metals and other compounds contaminating their production water in historical times. Great amounts of water were brought into contact with the paper pulp in historical paper mill process. The cellulose of the pulp acts as ion exchange material for heavy metals, forming a dynamic equilibrium.

Ancient papers from well dated and located books are eluted without destruction of their paper and the resulting solution is analysed towards its contaminants, caused either by the storing of the books in library (airborne contaminants) or by adsorption from its production water (water-borne contaminants) with modern methods of instrumental analysis. 
In case of airborne contaminants like $\mathrm{NO}_{x}, \mathrm{SO}_{x}, \mathrm{HCl}$, organic acids it is possible to prove that acids in the paper are not only introduced by production, but to a great extend as well trapped from environment. We further on show, that some organic acid are set free by the books into the environment.

A well defined pulp production process, starting with used clothes, so allows to estimate the historical heavy metal concentration $\left(\mathrm{Cu}^{2+}, \mathrm{Pb}^{2+}, \mathrm{Zn}^{2+}, \mathrm{Cd}^{2+}\right)$ in the production water.

In a flow-system the paper is first eluted and then the eluted paper spot is equilibrated with different concentration of heavy metals to plot the adsorption isotherm of that very spot.

Both data together allow a calculation of the heavy metal content of the historical river. For different waters of Germany and the Netherlands of the 16.-18. century the heavy metal load could be estimated. The resulting concentrations mostly were similar to the level of modern surface waters, but in the case of the dutch waters of the 17 . century, they were e.g. for $\mathrm{Pb}^{2+}$ significantly higher than modern values.

In summary this new field of research opens a new source of environmental historical data, which may at least help to understand local environmental processes and the long time stability of paper.

\section{Author details}

Jürgen Schram*, Rasmus Horst, Mario Schneider, Marion Tegelkamp, Hagen Thieme and Michael Witte

Instrumental \& Environmental Analysis, Dep. Chemistry, Niederrhein University of Applied

Sciences, Germany

\section{Acknowledgement}

This work was funded by the Research fund of the University of Applied Sciences Niederrhein in Krefeld / Germany. The authors are grateful to the staff of Shimadzu Europe, Duisburg, Germany, specially to Uwe Oppermann who promoted the work with technical support concerning atomic absorption spectroscopy. Thanks to the library of St.Josef, Krefeld, Germany (C. Zettner) and the Brigitten Bibliothek, Kaldenkirchen, Germany (K.J. Dors $\dagger$ ) for the possibility to measure books out of their book inventory.

\section{References}

[1] P. J. Barrett, M. Sarti, M. Wise and W. Sherwood, Terra Antartica, 2000, 7(1/2), 209,

[2] Ch. R. Fielding, Ch. Thomson, MRA, Terra Antartica, 1999, 6(1/2), 173 pp ,

\footnotetext{
${ }^{*}$ Corresponding Author
} 
[3] B. Wennrich, M. Wagner, P. Melles and P. Morgenstern, Int J Earth Sci (Geol Rundsch), 2005. 94: 275,

[4] S. Baron, M. Lavoie, A. Ploquin, J. Carignan, M. Pulido, and J.-L. De Beaulieu; Environ. Sci. Technol., 2005, 39, (14), 5131,

[5] J. Schram, T. Schmidt, M. Tegelkamp, Nachrichten aus Chemie, Technik und Laboratorium; NCTLDI, 1999, 47 (12) 1430,

[6] J. Schram, M. Schneider, R. Horst and H. Thieme, J. Environ. Monit., 2009, 11, 1101-1106

[7] J. Havermans, Environmental influences on the deterioration of paper, Rotterdam 1995,

[8] J. Havermans, Restaurator 1995, 16, 209,

[9] Guo,-YH; Zhao,-XL; Liu,-CM; Fenxi-Huaxue. Mar 1996; 24(3): 341-343,

[10] [10] Pekol,-TM; Cox,-JA; Environ-Sci-Technol. Jan 1995; 29(1): 1-6,

[11] [11] Horvath,-Z; Lasztity,-A; Zih-Perenyi,-K; Levai,-A.; Microchem-J. Nov 1996; 54(4): 391-401,

[12] Richardson,-DE; Jewell,-IJ; Appita. Mar 1985; 38(2): 113-118,

[13] Petherbridge, G.; Conservation of Library and archive Materials and the graphic Arts; London 1986,

[14] Smith, R.D.; The paper conservator, 12 (1988), 31,

[15] J.Schram; Th. Schmidt; "Aniquarische Bücher als Senke luftgetragener Schadstoffe"; Jahrestagung "Archäologie und Denkmalpflege" der GDCH; Vortrag/Tagungsband Würzburg 1998, S.52,

[16] Cox,-D; Jandik,-P; Jones,-W.; Pulp-Pap-Can. Sep 1987; 88(9): 90-93,

[17] Catalogue of the Library of the former Brigittenklosters St.Clemens in Kaldenkirchen/ Germany,

[18] Ch. J. Biermann, Handbook of Pulping and Papermaking. San Diego: Academic Press. 1993,

[19] T. Schönfeld und E. Broda, Microchimica Acta, 1951, 36,1, 537,

[20] Z. Horvath, A. Lasztity, K. Zih-Perenyi, A. Levai, Microchem-J. Nov 1996; 54(4), 39,

[21] J. Kintrup, G. Wünsch, Wasserwirtschaft, Abwasser, Abfall, 2001, 48(8), 1068,

[22] D. Laschka, m. Trumpp, Korrespondenz Abwasser, 1991, 38, 495,

[23] N. v. Richthofen, Einsatz von Multielementanalysen für Sielhäute und Klärschämme zur Indirekteinleiteridentifizierung, Universität Hannover Inst.f. Siedlungswasserwirtsch. u. Abfalltechn., 2005,

[24] S. B. Smith, Jr and G. M. Hieftje, Applied Spectroscopy, 1983, 37 (5), 419,

[25] Funk, Werner / Dammann, Vera / Donnevert, Gerhild: Qualitätssicherung in der Analytischen Chemie, Wiley-VCH Verlag, Weinheim 2005(2),

[26] Miller, James M. / Crowther, Jonathan B. (Hrsg.): Analytical Chemistry in a GMP Environment, John Wiley \& Sons, Inc., New York 2000,

[27] H. Özmen, F. Külahcı, A. Çukurovalı and M. Dogru, Chemosphere, 2004, 55,3, 401,

[28] B.J. Alloway, T. Reimer, R. Eis, Schwermetalle in Böden, Springer, 1999,

[29] W. F, Vincent, J.A.E. Gibson, M.O. Jeffries, Polar Record, 2001, 37 (201): 133, 
Cellulose - Medical, Pharmaceutical and Electronic Applications

[30] Wasserzeichensammlung Piccard, Piccard online, Hauptstaatsarchiv Stuttgart, http://www.piccard-online.de, 